\title{
Leprosy.
}

E. Muir.

PART I.

Extracts from a Chapter on Leprosy in "A System of Bacteriology in Relation to Medicine," Vol.V. (Privy Council, Medical Research Council).

THE only evidence of the vital persistence of $* \mathrm{~B}$. lepræ outside the human body is afforded by a few scattered instances of patients who have developed lesions under circumstances which pointed to the infection having remained alive for some time on some instrument, fabric or other article. A few illustrations may be mentioned :(1) A highly infective cook worked in a household for some years, with the result that his employer developed the disease. (2) A boy with bare knees played about in a house formerly inhabited by an infectious leper, and from which all the furniture had been removed by the previous occupant, except the mats on the floors ; the boy afterwards developed leprous lesions, but on his knees alone ; (3) Hansen mentioned the case of a young man showing signs of infection one year after he had worn a pair of old drawers given him by a leper; (4) Ginders records a statement by a Maori chief that, when leprosy was formerly prevalent, it was spread by giving the sleeping mat or clothes of a leper to an enemy. 'The absence of positive cultural and inoculation findings, however, makes more accurate knowledge impossible.

The power of B. lepræ to persist inside the human body and the analogies of tuberculosis and rat leprosy help to give us data from which the degree of extracorporeal vital persistence can at least be guessed at.

\section{SOURCE OF INFECTION.}

The impossibility of obtaining positive results either in vitro or by animal experiments makes it unlikely that $\mathrm{B}$. lepræ ever multiplies in nature outside the human body. While it is possible that it may remain alive for a considerable time outside the tissues, there seems to be much evidence that infection is as a rule due to prolonged and close contact

The recent International Conference on Leprosy held in Manila recommended that the organism of leprosy should be referred to as Mycobacterium leprae.Editor. 
with patients suffering from the types of leprosy in which $B$. lepræ are found in very large numbers ( $B^{3}$ cases $)$. In these cases acid-fast bacilli are shed from ulcerating nodules, abrasions of the skin, in the nasal discharge and in the droplets of saliva which are expelled from the mouth when patients shout, sing, cough or breathe violently. The presence of the organisms in droplets may be proved by placing a glass slide before the mouth of such a patient when coughing, and then fixing and staining, when numbers of acid-fast bacilli may be found. While such patients are always potential sources of infection, they are even more so in the reactionary phase. It is then that nodules ulcerate and discharge bacillusladen pus, and that the nasal discharge is more profuse. In this phase also, B. lepræ are found in the fæces, doubtless having been swallowed with the saliva, and in the urine, having been carried in the blood-stream from breaking-down lepromata to the kidneys.

The most dangerous patients are of ten those who, without showing any marked outward signs of leprosy, discharge organisms from the nose or from ulcerating nodules under their clothes. In countries where the disease is endemic, like India, such patients are not at all uncommon. It should be noted that the majority of ulcers on the fingers and toes are trophic in nature, and seldom contain infection. Of 250 leprous ulcers examined by the author at the Purulia leper asylum, only three showed acid-fast organisms; the remaining 247 were trophic ulcers. It is remarkable that the public and even some physicians look upon these trophic ulcers as the chief source of danger, and wish to isolate patients suffering from them, while not recognizing the true danger in the infectious cases mentioned above.

\section{INSECT CARRIERS.}

The possibility of transmission of leprosy by insects has been carefully considered by various workers. As shown by Marchoux and Bourret, the mechanical carriage of organisms on the feet of house flies is a not unlikely method of transmission. Evidence as to the infection of the gut of flies is conflicting; the India Commission of 1890-91 found all trials negative, but other investigators have found on an average 50 per cent. of infected flies.

Scabies is a common disease among lepers and the classes among which leprosy is common. The gut of Acarus scabiei found on lepers is seldom infected, but there is no doubt that auto-inoculation is favoured by the scratching induced by the presence of this parasite. The same is true of lice 
and tics. Bed bugs are also qualified to carry infection. Rogers and Muir (1925) summarize the investigations of eight workers who found on an average infected gut in 9.9 per cent. of bugs fed on lepers, but only 0.88 per cent. positive when the insects were collected from the beds of lepers.

Only four out of 631 mosquitoes caught on lepers by various workers were found positive.

Lebœuf (1912), after doing a considerable amount of work at this subject, reviewing his own work and that of others, considers that, though insects may help in the transmission of leprosy, the part they play is at most an insignificant one.

Míethods of Transmission.

$\mathrm{Up}$ to the end of the eighteenth century the generally accepted theory was that leprosy is a disease which is spread by contagion. But in the nineteenth century, largely due to the teaching of the Norwegian authorities, Danielssen and Boeck, in their book published in 1848, the theory of heredity became popular. This was upheld by a special committee of the Royal College of Physicians of London in 1862. Even as late as 1891 , the special India Leprosy Commission placed in their report: " $T$ hough in a scientific classification of diseases leprosy must be regarded as contagious and also inoculable, yet the extent to which it is propagated by these means is exceedingly small." Hutchinson, at that time one of the greatest authorities on leprosy, held that leprosy was caused by the eating of decomposing and badly preserved fish ; commenting upon the report of the India Commission in 1890-91, twenty years after the discovery of the specific organism by Hansen, he wrote: "I feel convinced that if leprosy be contagious at all, it depends but to an almost infinitesimal extent upon contagion for its spread." Fortunately the Executive Committee, who appointed the India Commission repudiated their views and declared in favour of contagion. All subsequent authorities and conferences have declared in favour of leprosy being a contagious disease, and the International Conference which met at Strasbourg (in 1923) based all their resolutions upon this understanding : "Il faut faire savoir aux populations que la lepre est une maladie contagieuse."

The question of intrauterine transmission is also a difficult one. Pineda has shown that infection of the placenta and cord is not infrequent, and he has found post-natal infection in the child. Rodrigues reports four out of fifteen placentas infected. Sugai and Mononobe (1913) state that 
they found B. lepræ in small numbers in the circulating blood of ten out of twelve children born of leprous parents, and in the placenta in nine cases; and also that the specific organism was found in the blood of a new-born child whose mother was not leprous, but whose father was. They also write that, if lepra bacilli are injected intravenously into pregnant rabbits, they are found after twenty-four hours in the heart of the fœtus.

The unanimous opinion of all, however, seems to be that, with one or two possible exceptions, children who are separated from their leprous parents at birth, and are thereafter kept free from all chance of infection, do not develop leprosy, and that for practical purposes leprosy may be regarded as due to post-natal transmission.

\section{Portals of Entrance.}

The possible portals of entrance are the nasal, buccal and pharyngeal mucosa, the skin and the respiratory and gastrointestinal tracts.

Stricker promulgated the theory that the nasal mucosa was the most frequent site of inoculation, as he found bacilli in over 83 per cent. of nasal septa in lepers. Kitasato found numerous bacilli in the epithelial cells of the noses of eight out of sixty-eight healthy persons who were either the children of lepers or were living with them. On the other hand, Brinkerhoff and Moore (1909) made a nasal examination of 392 healthy persons in a highly endemic area, and found only one infected ; and in Culion Leper Colony Solis and Wade (1925) found that of 250 children living with leprous parents, no child showed primary nasal infection who did not at the same time show positive skin lesions. It is possible that in cold climates, where the body is more protected by clothes and nasal catarrh is more common, the nose is more liable to inoculation than in warmer countries where the skin is less protected and, therefore, more liable to abrasions through which infection might enter. The fact that acid-fast bacilli are not found in the nasal mucosa does not, however, preclude the possibility that inoculation has taken place through the mucous membrane of the nasal septum. In early skin lesions, smears and sections frequently fail to show any acid-fast organisms ; it is also possible that early nasal lesions may fail to give positive bacteriological results when a scraping is examined. In favour of this may be mentioned the frequent history, noticed by the author, of dry rhinitis preceding more definite signs of leprosy.

There is little or no evidence for or against a primary infection of the buccal and pharyngeal mucosa, lesions of 
these parts not becoming evident until they are well established in the skin of the face.

The skin is the most frequent site of first-noticed lesions. One thousand and fifty histories of these were collected by the author from all parts of India. The face, ears and external or extensor surfaces of the limbs showed the largest number ; while the scalp, neck, flexor aspects of the limbs, the abdomen and especially the waist were comparatively exempt. It was noticed that lesions of the feet were more common in stony districts, but seldom occurred in alluvial districts without stones. It is not contended that these first-noticed lesions indicate the sites of inoculation and represented definite primary lesions comparable with those found in syphilis. In some cases they may have been primary, but in others some local injury may have located an infection preexisting in the body.

The question of insect transmission has been mentioned above, and it is probably that the chief rôle of insects is not as vectors, though they may act as such to a certain extent, but as sources of irritation leading through their bites to auto-inoculation, the patients scratching in the organisms lying under their nails or on the surface of the body.

There is no positive evidence as to respiratory infection. Leprosy of the lungs does occur, but its infrequency and the fact that it only appears in cases in which the disease is well established in other parts of the body, are against this being a common portal of infection.

The gastro-intestinal tract does not show lesions, but this is no reason why it may not be a portal of entry. It has been shown that tubercle bacilli and even carbon atoms can be carried through the gastro-intestinal mucosa into the body, and it is possible that lepra organisms may enter in the same way. In support of this may be mentioned the analogy of rat leprosy. Marchoux was able to infect rats with this disease by feeding them on rat leprosy material, and the author and Henderson have done the same.

The probability is that the nasal septum, the skin and the gastro-intestinal tract are all portals of entry, that the frequency with which each of these is implicated varies with different countries, customs and other circumstances, but that the relative frequency of each is a matter which is not at present known.

Factors Influencing Transmission.

There are four factors which very markedly influence transmission :- 
(a) The closeness of contact. There is abundant evidence to show that while leprosy may be transmitted by occasional and casual proximity it is much more frequently associated with a house, room, and, most of all, a bed infection. The joint family system in India, the common, family box bed in colder regions, sexual and sartorial promiscuousness, and the close contact of the child with its mother in the earlier years are all important factors in the spread of infection.

(b) The length of contact. The longer the contact the more are the chances of transmission taking place.

(c) The infectiousness of the patient. This is very important, and is a factor that has not been sufficiently considered. It is in the nodular skin type $\left(\mathrm{B}^{2}\right.$ and $\left.\mathrm{B}^{3}\right)$ that the danger really lies.

(d) The state of health and natural resistance of the person who comes in contact. There is reason to believe that the healthy human body is not as a rule subject to leprous infection, and that when the disease occurs it is due to lowering of resistance plus infection.

(To be continued.)

We are indebted to the Controller of H.M. Stationery Office for permission to reprint this article--Editor. 